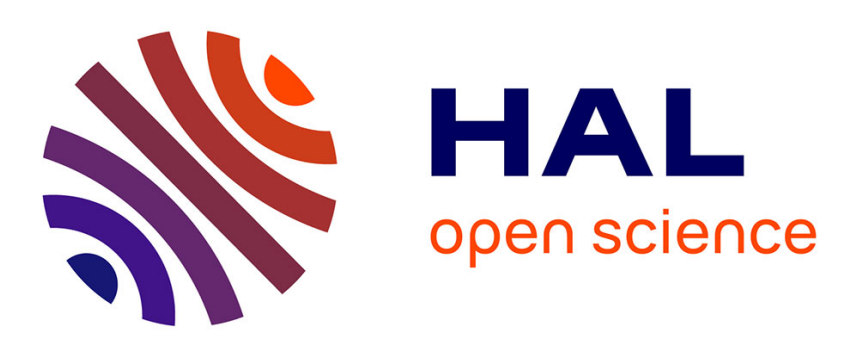

\title{
Percolation of single-walled carbon nanotubes in ceramic matrix nanocomposites
}

\author{
Sébastien Rul, Florent Lefèvre-Schlick, Ennio Capria, Christophe Laurent, \\ Alain Peigney
}

\section{> To cite this version:}

Sébastien Rul, Florent Lefèvre-Schlick, Ennio Capria, Christophe Laurent, Alain Peigney. Percolation of single-walled carbon nanotubes in ceramic matrix nanocomposites. Acta Materialia, 2004, vol. 52, pp. 1061-1067. 10.1016/j.actamat.2003.10.038 . hal-00917575

\section{HAL Id: hal-00917575 \\ https://hal.science/hal-00917575}

Submitted on 12 Dec 2013

HAL is a multi-disciplinary open access archive for the deposit and dissemination of scientific research documents, whether they are published or not. The documents may come from teaching and research institutions in France or abroad, or from public or private research centers.
L'archive ouverte pluridisciplinaire HAL, est destinée au dépôt et à la diffusion de documents scientifiques de niveau recherche, publiés ou non, émanant des établissements d'enseignement et de recherche français ou étrangers, des laboratoires publics ou privés. 


\section{OATAO \\ Open Archive Toulouse Archive Ouverte}

\section{Open Archive TOULOUSE Archive Ouverte (OATAO)}

OATAO is an open access repository that collects the work of Toulouse researchers and makes it freely available over the web where possible.

This is an author-deposited version published in : http://oatao.univ-toulouse.fr/ Eprints ID : 10445

To link to this article : DOI:10.1016/j.actamat.2003.10.038

URL : http://dx.doi.org/10.1016/j.actamat.2003.10.038

To cite this version :

Rul, Sébastien and Lefèvre-Schlick, Florent and Capria, Ennio and Laurent, Christophe and Peigney, Alain Percolation of single-walled carbon nanotubes in ceramic matrix nanocomposites. (2004) Acta Materialia, vol. 52 ( $\left.\mathrm{n}^{\circ} 4\right)$. pp. 1061-1067. ISSN 1359-6454

Any correspondance concerning this service should be sent to the repository administrator: staff-oatao@listes-diff.inp-toulouse.fr 


\title{
Percolation of single-walled carbon nanotubes in ceramic matrix nanocomposites
}

\author{
S. Rul, F. Lefèvre-schlick, E. Capria, Ch. Laurent, A. Peigney * \\ Centre Interuniversitaire de Recherche et d'Ingénierie des Matériaux, UMR CNRS 5085, University Paul Sabatier, 118 route de Narbonne, \\ F-31062, Toulouse, cedex 4, France
}

\begin{abstract}
The percolation of carbon nanotubes (CNT) in an electrical insulating ceramic is studied for the first time. The in situ synthesis of the CNT (0.2-25 vol\%) by a CCVD route allows to achieve their homogeneous distribution in the spinel matrix. Up to 11 vol\% CNT, the DC electrical conductivity $(\sigma)$ is well fitted by the scaling law of the percolation theory $\sigma=k\left(p-p_{\mathrm{c}}\right)^{t}$ with a low percolation threshold $p_{\mathrm{c}}=0.64 \mathrm{vol} \%$. At the threshold, $\sigma$ jumps over seven order of magnitude (from $10^{-10}$ to $0.0040 \mathrm{~S} \mathrm{~cm}^{-1}$ ) and then reaches a maximum at $8.5 \mathrm{~S} \mathrm{~cm}^{-1}$. The results are discussed in relation with the characteristics of the CNT, their damaging during the hot-pressing at $1300{ }^{\circ} \mathrm{C}$ and the microstructure of the composites. CNT-ceramic composites become attractive materials not only for their enhanced mechanical properties, but also for the possibility to tailor the electrical conductivity through the CNT content.
\end{abstract}

Keywords: Hot-pressing; Electrical conductivity; Scanning electron microscopy; Nanocomposite; Percolation

\section{Introduction}

Multiple applications are envisioned for carbon nanotubes (CNT), notably as part of a new class of nanocomposite materials and therefore many research works are currently devoted [1] to their incorporation into a metal-, ceramic- or, more commonly, polymermatrix. The composites are generally prepared by mixing the desired quantity of single- or multi-walled carbon nanotubes (SWNT and MWNT, respectively) with the matrix, which is either dissolved or in suspension in a liquid medium, before further treatments. Many authors have aimed at using CNT in order to enhance the mechanical properties of composites. In the case of ceramic materials, CNT seem to be efficient toughening agents leading to less brittle materials, i.e., to composites with a significantly higher fracture toughness than the corresponding ceramic [2-6]. CNT can also enhance the tribological behaviour of ceramics [7]. It has been demonstrated that CNT can confer an electrical conductivity to otherwise insulating polymers without altering their other properties since a very low volume fraction (below $1 \mathrm{vol} \%$ ) is sufficient for the percolation of the CNT network [8-12]. This unique performance is due to the enormous aspect ratio of CNT, which can reach more than 1000, particularly for SWNT synthesized by a catalytic chemical vapour deposition (CCVD) method. However, both this very high aspect ratio and the very small CNT diameter (no more than a few $\mathrm{nm}$ ) induce many difficulties to satisfactorily disperse the CNT within the matrix and to avoid the formation of balls of entangled CNT, particularly when the matrix material is in the granular form such as a ceramic powder. To resolve such problems, the present authors have proposed the in situ CCVD synthesis of CNT within the oxide powders [13]. In the obtained composite powders $\left(\mathrm{Al}_{2} \mathrm{O}_{3}, \mathrm{MgAl}_{2} \mathrm{O}_{4}\right.$ or $\mathrm{MgO}$ matrix), the CNT, mainly single- and double-walled, are very homogeneously distributed. This excellent distribution is maintained in the dense composite prepared by 
hot-pressing these composite powders [14-16]. It has been shown that CNT confer an electrical conductivity to such composites, in the range $0.2-4.0 \mathrm{~S} \mathrm{~cm}^{-1}$ for 2.8 $5.7 \mathrm{wt} \%$ of carbon, respectively [16]. The electrical conductivity was attributed to the percolation of the network of CNT since it is fairly well correlated to the relative quantity of CNT and since the specimens become insulators when the CNT were destroyed [16]. It was also shown that an alignment of CNT within the ceramic matrix by high-temperature extrusion of the samples leads to a strong anisotropy in the electrical conductivity [17].

The electrical conductivity of CNT-polymer materials due to the percolation of CNT has been widely investigated [8-12], but only a few authors have reported the electrical conductivity of CNT-ceramic composites. Recently, Zhan et al. [18] have prepared such composites using 5.7-15 vol\% SWNT self-organized in ropes, which were mixed with nanocrystalline alumina. For 15 vol $\%$ $\mathrm{CNT}$, an electrical conductivity of $33.45 \mathrm{~S} \mathrm{~cm}^{-1}$ was obtained, higher than was previously reported by our group $[16,17]$. These results have confirmed that CNT provide efficient electrical discharge to insulating ceramic matrix [16-18], similarly to what they do in an insulating polymer matrix. However, no work has yet been reported to characterise and quantify the percolation of SWNT in an insulating ceramic matrix. In the present paper, we report the preparation of a family of 22 different CNT-Co/Mo- $\mathrm{MgAl}_{2} \mathrm{O}_{4}$ composites containing between 0.23 and $24.5 \mathrm{vol} \% \mathrm{CNT}$. We show that the electrical conductivity of the dense materials is controlled in the range $0.004-8.50 \mathrm{~S} \mathrm{~cm}^{-1}$ by the CNT content. We demonstrate that for samples containing less than $10 \mathrm{vol} \% \mathrm{CNT}$, the electrical conductivity versus the CNT content $\left(p-\operatorname{vol}^{\%}\right)$ satisfactorily follows the percolation scaling law $\sigma=k\left(p-p_{\mathrm{c}}\right)^{t}$ with a threshold $p_{\mathrm{c}}=0.64 \mathrm{vol} \%$ and an exponent $t=1.73$. In all the composite powders, CNT are similar and of high quality, $70-90 \%$ being SWNT and most of the others being double-walled, without carbon nanofibres nor significant amount of disordered carbon. CNT have been synthesized in situ and thus are very well distributed between the matrix grains and this also obviates the need for any purification or dispersion treatments which could have altered the characteristics of the CNT.

\section{Experimental procedure}

The synthesis method of powders of $\mathrm{MgAl}_{2} \mathrm{O}_{4}$-based oxide solid solution by the nitrate-urea combustion method was described elsewhere [19]. The powders were attritor-milled and the ceramic foams were prepared either by impregnating a polymeric foam with an aqueous suspension of solid solution (samples labeled IF), or by a gelcasting-foam method reported in a pre- vious paper [20] (samples labeled GF). A calcination in air is used to remove the organic components. The in situ synthesis of SWNT is made in a flowing $\mathrm{H}_{2}-\mathrm{CH}_{4}$ gas mixture, generally at $1000{ }^{\circ} \mathrm{C}$. The composite powders are uniaxially hot-pressed in graphite dies at $43 \mathrm{MPa}$, in a secondary vacuum $\left(P<10^{-4}\right.$ Torr $)$, at $1300{ }^{\circ} \mathrm{C}$. The so-obtained dense pellets $(10 \mathrm{~mm}$ in diameter, $2.5 \mathrm{~mm}$ thick) were polished on the two faces. Then three parallelepipedic specimens were cut (minimum $5 \mathrm{~mm}$ in length) and coated with silver paste on their top surface.

The carbon contents in the composite powders were determined by flash combustion. The density of the dense composites was calculated from their measured weight and dimensions. The composite powders and the fracture surface of dense composites were observed with a high resolution field-effect-gun scanning electron microscopy (FEG-SEM - Hitachi S-4500). Some powders (C6, CM5 and CM12) were observed by high resolution electron microscopy (HRTEM - Jeol 2010) and the statistical studies on the number of walls and the CNT diameter were performed on more than 100 images of individual CNT for each sample. The electrical conductivity was measured under increasing DC potentials (0.05-0.3 V, current densities lower than $\left.160 \mathrm{~mA} / \mathrm{cm}^{2}\right)$ between the two top surfaces of the parallelepipedic specimen.

\section{Results and discussion}

The composition of the starting catalytic materials and their preparation modes are reported in Table 1, besides the characteristics of the corresponding hotpressed composites. To obtain such of a large variety of high quality samples, it was necessary to adapt the previously reported [19] synthesis method. For samples $\mathrm{C} 1-\mathrm{C} 5$, the catalytic material is a powder of a $\mathrm{Mg}_{1-x} \mathrm{Co}_{x} \mathrm{Al}_{2} \mathrm{O}_{4}(x=0.01)$ solid solution which was heat-treated in $\mathrm{H}_{2}-\mathrm{CH}_{4}$ atmosphere at 900, 925, 950, 975 and $1000{ }^{\circ} \mathrm{C}$, respectively, leading to a gradually higher reduction level of the $\mathrm{Co}^{2+}$ ions and thus to increased quantities of Co catalytic nanoparticles, which in turn results in higher quantities of in situ formed $\mathrm{CNT}$, in agreement to results previously reported for $\mathrm{Al}_{2-2 x} \mathrm{Fe}_{2 x} \mathrm{O}_{3}$ solid solutions [21]. For samples C6, C7 and $\mathrm{C} 8$, the higher reduction temperature $\left(1000^{\circ} \mathrm{C}\right.$, used for $\mathrm{C} 5$, was retained) but a higher amount of cobalt was used in starting $\mathrm{Mg}_{1-x} \mathrm{Co}_{x} \mathrm{Al}_{2} \mathrm{O}_{4}$ solid solution with $x=0.05,0.1$ and 0.2 , respectively. Thus, the quantity of Co catalytic nanoparticles obtained at $1000{ }^{\circ} \mathrm{C}$ is increased, leading to increased CNT contents [19]. To still increase the CNT fraction above the $2.50 \mathrm{wt} \%$ reached for $\mathrm{C} 8$, the characteristics of the catalytic material has been modified in three ways. Firstly, this material has been prepared in the form of a foam, as opposed to a 
Table 1

Characteristics of the oxide solid solutions used as catalytic materials during the CCVD synthesis of the single-walled carbon nanotubes : Co and Mo contents, preparation modes (P, powder, IF, foam prepared by impregnating a polymeric foam with an aqueous suspension of the solid solution powder, GF, foam prepared by a gelcasting-foam method [20], CA, starting powders prepared by using citric acid instead of urea during the combustion leading to a much higher specific surface area [22]). Characteristics of the hot-pressed composites: densification, $\varepsilon$-Co, $\mathrm{Mo}{ }_{2} \mathrm{C}$ and $\mathrm{CNT}$ contents and DC electrical conductivity $(\sigma)$

\begin{tabular}{|c|c|c|c|c|c|c|c|c|c|}
\hline \multirow[t]{2}{*}{ Sample } & \multicolumn{3}{|c|}{ Solid Solution } & \multicolumn{6}{|c|}{ CNT-MgAl ${ }_{2} \mathrm{O}_{4}$ composite } \\
\hline & $\begin{array}{l}\text { Co } \\
\text { (cat. } \% \text { ) }\end{array}$ & $\begin{array}{l}\text { Mo } \\
\text { (cat.\%) }\end{array}$ & $\begin{array}{l}\text { Preparation } \\
\text { mode }\end{array}$ & $d(\%)$ & $\begin{array}{l}\mathrm{Co} \\
\left(\mathrm{vol}^{\circ} \%\right)\end{array}$ & $\begin{array}{l}\mathrm{Mo}_{2} \mathrm{C} \\
\left(\mathrm{vol}^{\%}\right)\end{array}$ & $\begin{array}{l}\text { CNT } \\
\left(\mathrm{wt}^{0} \%\right)\end{array}$ & $\begin{array}{l}\text { CNT } \\
\left(\mathrm{vol}^{2} \%\right)\end{array}$ & $\begin{array}{l}\sigma \\
\left(\mathrm{S} \mathrm{cm}^{-1}\right)\end{array}$ \\
\hline $\mathrm{CMH}$ & 20 & 10 & $\mathrm{P}$ & 97.3 & 3.07 & $2.18(\mathrm{Mo})$ & 0 & 0 & $1 \times 10^{-10}$ \\
\hline $\mathrm{C} 1$ & 1 & 0 & $\mathrm{P}$ & 100 & 1.62 & 0 & 0.11 & 0.23 & $1 \times 10^{-10}$ \\
\hline $\mathrm{C} 2$ & 1 & 0 & $\mathrm{P}$ & 100 & 1.62 & 0 & 0.11 & 0.23 & $1 \times 10^{-10}$ \\
\hline $\mathrm{C} 3$ & 1 & 0 & $\mathrm{P}$ & 100 & 1.62 & 0 & 0.11 & 0.23 & $1 \times 10^{-10}$ \\
\hline $\mathrm{C} 4$ & 1 & 0 & $\mathrm{P}$ & 94.3 & 1.62 & 0 & 0.55 & 1.16 & 0.0040 \\
\hline $\mathrm{C} 5$ & 1 & 0 & $\mathrm{P}$ & 100 & 1.62 & 0 & 0.55 & 1.16 & 0.0072 \\
\hline C6 & 5 & 0 & $\mathrm{P}$ & 99.8 & 1.62 & 0 & 0.60 & 1.27 & 0.0087 \\
\hline $\mathrm{C} 7$ & 10 & 0 & $\mathrm{P}$ & 99.7 & 1.62 & 0 & 1.20 & 2.54 & 0.060 \\
\hline $\mathrm{C} 8$ & 20 & 0 & $\mathrm{P}$ & 98.3 & 3.14 & 0 & 2.50 & 5.27 & 0.200 \\
\hline C9 & 20 & 0 & IF & 95.8 & 3.13 & 0 & 2.60 & 5.48 & 0.240 \\
\hline $\mathrm{C} 10$ & 20 & 0 & GF & 92.7 & 3.08 & 0 & 3.70 & 7.74 & 0.530 \\
\hline CM1 & 10 & 5 & $\mathrm{P}$ & 86.6 & 1.51 & 1.30 & 4.40 & 9.37 & 0.895 \\
\hline $\mathrm{CM} 2$ & 20 & 10 & $\mathrm{P}$ & 83.8 & 2.86 & 2.47 & 5.10 & 11.18 & 1.00 \\
\hline CM3 & 20 & 5 & $\mathrm{P}$ & 81.0 & 2.89 & 1.25 & 5.10 & 13.52 & 2.53 \\
\hline CM4 & 20 & 10 & IF & 76.9 & 2.79 & 2.41 & 7.00 & 15.13 & 6.59 \\
\hline CM5 & 10 & 5 & GF & 76.6 & 1.44 & 1.25 & 7.20 & 15.01 & 6.74 \\
\hline CM6 & 20 & 10 & GF & 76.2 & 2.78 & 2.40 & 7.30 & 15.74 & 6.60 \\
\hline CM7 & 5 & 5 & GF & 79.9 & 0.73 & 1.25 & 7.50 & 15.54 & 6.57 \\
\hline CM8 & 20 & 5 & IF & 76.2 & 2.83 & 1.22 & 7.80 & 16.31 & 5.41 \\
\hline CM9 & 20 & 5 & GF & 73.4 & 2.82 & 1.22 & 8.00 & 16.70 & 7.00 \\
\hline CM10 & 10 & 5 & IF & 73.0 & 1.41 & 1.22 & 8.90 & 18.31 & 7.29 \\
\hline CM11 & 10 & 5 & IF (CA) & 70.5 & 1.37 & 1.19 & 10.70 & 21.72 & 7.96 \\
\hline CM12 & 10 & 5 & $\mathrm{GF}(\mathrm{CA})$ & 68.0 & 1.34 & 1.16 & 12.20 & 24.48 & 8.53 \\
\hline
\end{tabular}

powder. Foams have been obtained either by impregnating a polymeric foam with an aqueous suspension of the solid solution powder (samples labeled IF), or by a gelcasting-foam method [20] (samples labeled GF). During the CNT synthesis reaction, the supply of gases to the foam material is easier, which leads to a significant increase of the CNT content [20] (samples C9 and $\mathrm{C} 10$ ), in comparison with the corresponding powder catalytic material (sample C8). Secondly, we have synthesized new catalytic materials (CM1-CM12) that contain molybdenum as a catalytic promoter [22]. The resulting increase of the CNT content is significant for powders (CM1-CM3) and is much more pronounced for foam materials (CM4-CM10). Thirdly, two more foams were prepared from starting powders having a much higher specific surface area (prepared by using citric acid instead of urea in the combustion method [22]), leading to a further increase of the CNT content for specimens CM11, CM12, up to $12.20 \mathrm{wt} \%$.

High resolution SEM observations were conducted on the composite powders and some typical images are reported in Fig. 1. In the $\mathrm{C} 1$ sample (Fig. 1(a)), only a few CNT are observed between the oxide grains (200$500 \mathrm{~nm}$ ). The CNT form a very well-distributed interconnected web for C6 (Fig. 1(b)). More and more CNT are observed in samples C7 (Fig. 1(c)), CM5 (Fig. 1(d)), CM10 (Fig. 1(e)) and CM12 (Fig. 1(f)), in agreement with the carbon contents reported in Table 1. In addition, the filament diameters increase gradually from a few nanometres for $\mathrm{C} 1$ and $\mathrm{C} 6$, which corresponds mainly to individual CNT, up to $10-20 \mathrm{~nm}$ for CM12, which corresponds to bundles made up of several CNT. HRTEM observations (not shown) performed on C6, CM5 and CM12 have confirmed that most bundles are not well-crystallized ropes but rather merely are a gathering of CNT, generally with different characteristics, which occurs after the CNT formation. The samples do not contain any large MWNT nor carbon fibres. Statistical studies on HRTEM images have shown that $70-90 \%$ of the CNT are SWNT, most of the others being double-walled and, in C6 only, a few $(<5 \%)$ having 3, 4 or 5 walls. It was also revealed that the CNT diameter is in the $0.5-5 \mathrm{~nm}$ range with a mean diameter between 2.4 and $2.8 \mathrm{~nm}$, which is slightly larger than for the CNT generally used to prepare composites. Since the CNT characteristics in these three samples (C6, CM5 and CM12) are similar although the CNT quantities are very different $(0.60,7.20$ and $12.20 \mathrm{wt} \%$, respectively), it was considered that the CNT have similar characteristics in all the 22 CNT-ceramic composites. From these com- 

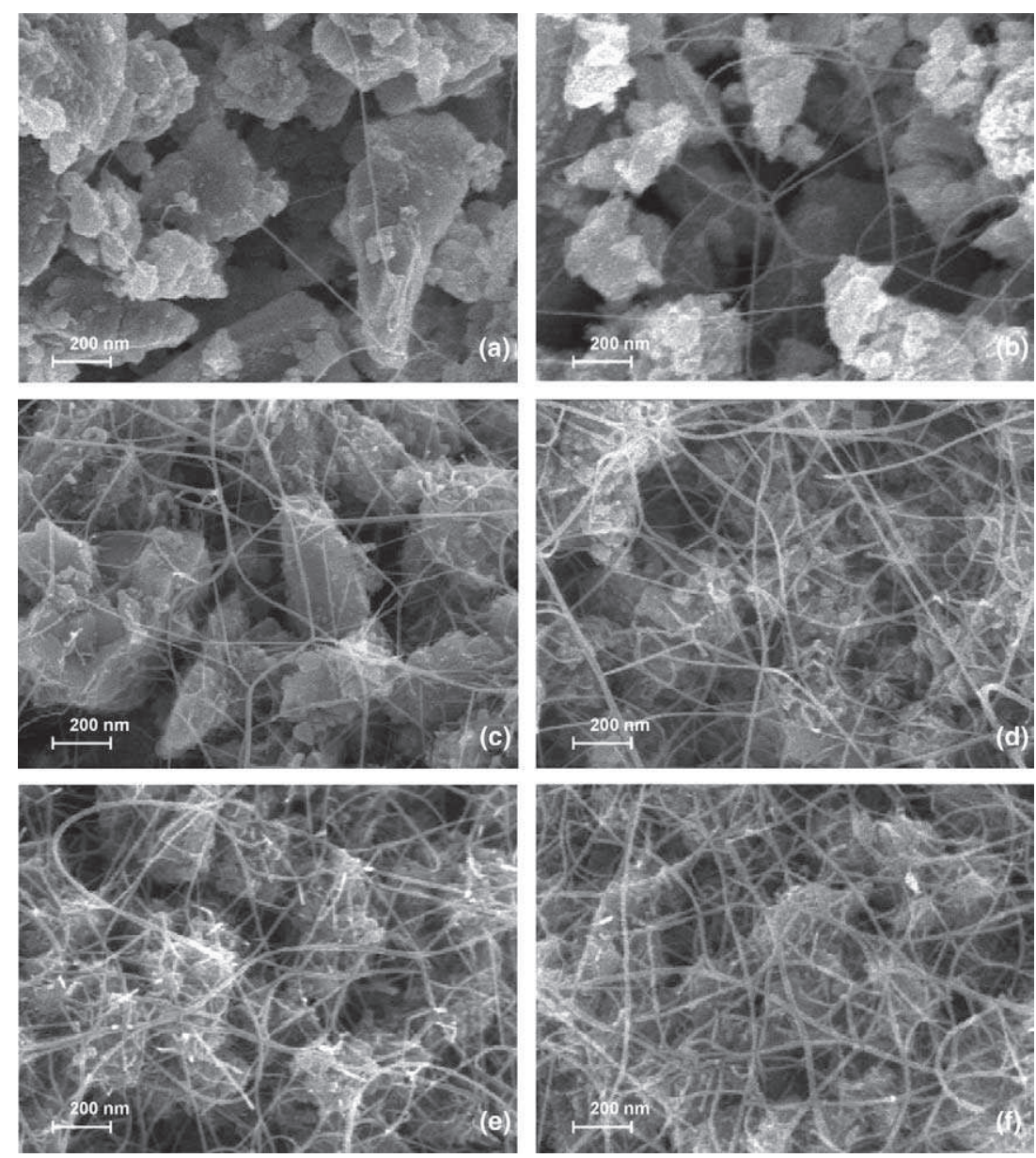

Fig. 1. High resolution SEM images of some of the CNT-MgAl $\mathrm{O}_{4}$ composite powders: (a) Sample C1 showing only a few CNT between the oxide grains. (b)-(f) Samples C6, C7, CM5, CM10 and CM12, respectively, showing that more and more CNT are observed, in agreement with the carbon contents reported in Table 1, and are very well distributed, forming a continuous network between the oxide grains. The filament diameter increases gradually due to the gathering of CNT into bundles which becomes more pronounced when the quantity of CNT increases.

mon characteristics, a CNT density of 1.70 was calculated and was used to calculate the CNT vol\% from the experimental CNT wt\%. HRTEM observations also showed that the specimens do not contain significant amount of disordered carbon, the only non-tubular carbon form being capsules surrounding some Co nanoparticles. Because these capsules represent a negligible quantity of carbon compared to CNT, we have considered that the carbon content is representative of the CNT content (Table 1). X-ray diffraction performed on all the composite samples revealed the presence of $\varepsilon$ $\mathrm{Co}$ and some $\mathrm{Mo}_{2} \mathrm{C}$ (CM samples) besides the $\mathrm{MgAl}_{2} \mathrm{O}_{4}$ matrix. From the chemical composition of the samples, we have deduced the volume contents in $\varepsilon-\mathrm{Co}$ and $\mathrm{Mo}_{2} \mathrm{C}$ (Table 1) and it is noted that the values are not higher than 3.08 and $2.47 \mathrm{vol} \%$, respectively. In CM samples, the carbon contained in $\mathrm{Mo}_{2} \mathrm{C}$ is negligible when compared to that in the CNT. For the sake of comparison, an oxide material containing the larger amounts of cobalt and molybdenum used in this study (as in CM2, $\mathrm{CM} 4$ and CM6) has been heated up to $1000{ }^{\circ} \mathrm{C}$ in pure
$\mathrm{H}_{2}$, as opposed to $\mathrm{H}_{2}-\mathrm{CH}_{4}$, leading to a composite (sample labeled $\mathrm{CMH}$ ) containing metallic $\varepsilon$-Co (3.07 vol $\%)$ and Mo $(2.18$ vol\%) but of course without any CNT.

It was chosen to hot-press the materials at only $1300^{\circ} \mathrm{C}$, i.e., at a lower temperature than that used in our previous studies $\left(1500^{\circ} \mathrm{C}\right)[16]$, with the aim to avoiding, or at least to decreasing, any damage to the CNT at high temperature. As shown in Table 1, only the samples containing less than $5.3 \mathrm{vol} \%$ of $\mathrm{CNT}(\mathrm{CMH}, \mathrm{C} 1-\mathrm{C} 8)$ have been successfully densified. For the other specimens, the densification quite regularly decreases with the CNT content, remaining very low for CM12 (68.0\%). As previously reported [16], CNT greatly inhibit the matrix grain growth, which is very unfavourable to the densification when the CNT content is too high. Also, CNT probably inhibit the uniaxial pressure action owing to their elastic behaviour. These phenomena are particularly effective in the present samples in which, due to the in situ synthesis of CNT, all the matrix grain are surrounded by the web of CNT bundles. These results confirms that the 
influence of CNT on the matrix microstructure and densification is more and more pronounced when the CNT content is increased, and this up to about $25 \mathrm{vol} \%$. It would probably be very difficult to fully densify such composites with a very high CNT content. Zhan et al. $[2,18]$ have successfully densified SWNT-ceramic composites using spark-plasma sintering (SPS) instead of hot-pressing. These authors used another matrix (nanocrystalline alumina) which was mixed with up to $15 \mathrm{vol} \%$ CNT of characteristics (SWNT in the form of ropes of 10100 CNT) different than those of the present samples. By contrast, for the same CNT content (sample CM5), we obtain only $76.6 \%$ in densification. The benefit of the SPS method, the more favourable microstructure of the green materials and the necessarily less-achieved distribution of the CNT around the matrix grains $[2,18]$ all contribute to explain the difference.

High resolution SEM images of the fracture surface of the hot-pressed composites are shown in Fig. 2. The
CMH sample (Fig. 2(a)), i.e., the one which does not contain CNT, shows a rather smooth surface due to a mainly transgranular fracture mode which is characteristic of metal-ceramic nanocomposites [23]. A few CNT are apparent on the fracture surface of C5 (Fig. 2(b)), the matrix grains (about $200 \mathrm{~nm}$ in diameter) of which are more easily observable than for CMH. Note that the CNT that have been broken at the level of the fracture surface can not be seen on these images, resulting in an under-estimation of the real quantity of CNT in the composites. The $\mathrm{C} 10$ and CM2 samples (Fig. 2(c) and (d)) greatly differ from $\mathrm{C} 5$ by showing smaller matrix grains due to the more pronounced grain-growth inhibition effect of CNT. Moreover, some long CNT are visible emerging out of the pores and some $\mathrm{CNT}$ have been cut near the fracture surface and just appear after some pull-out. In the latter parts of the specimen, the fracture mode seems to still be transgranular. On the CM5 and CM12 samples (Fig. 2(e) and (f)), the matrix
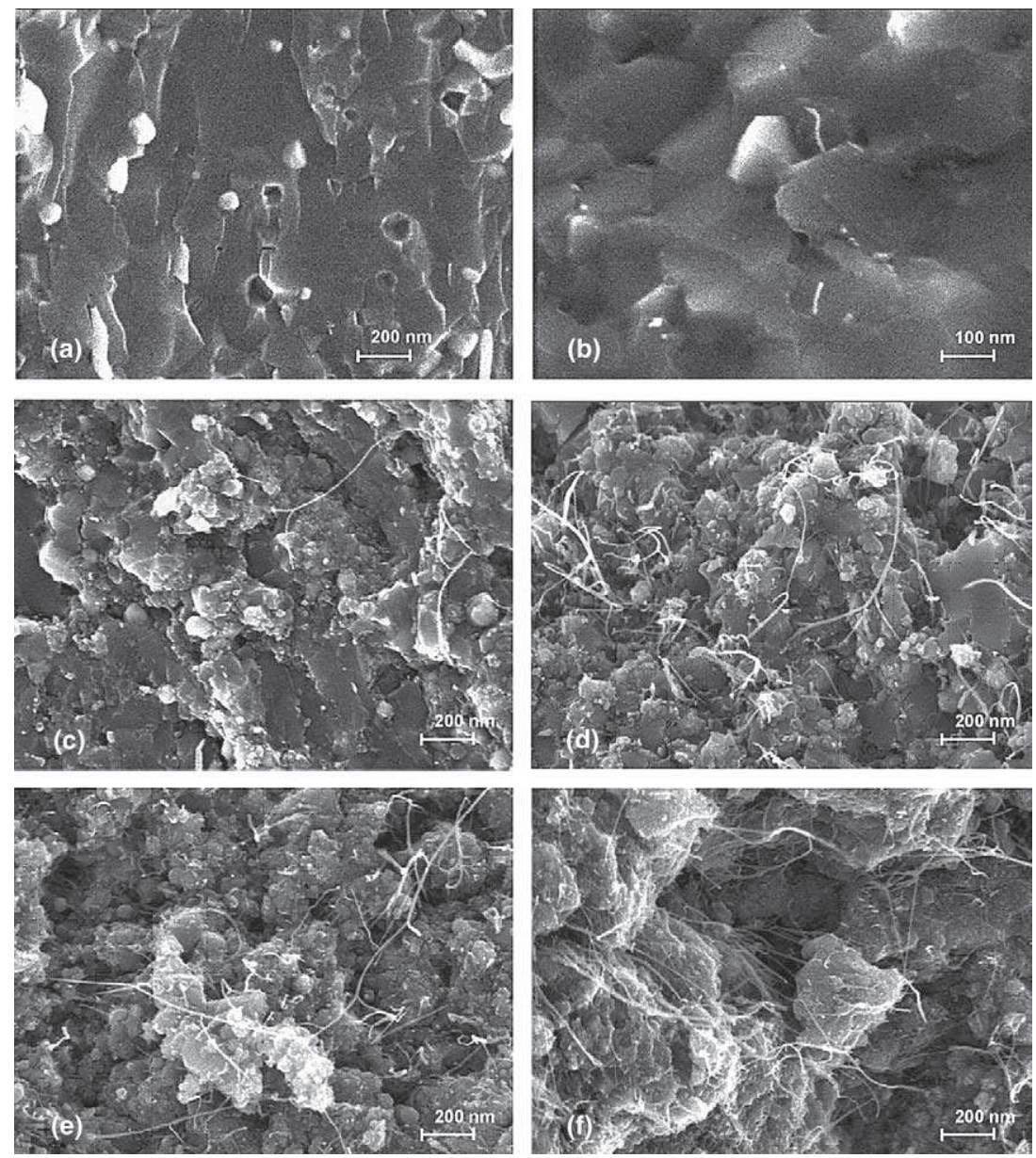

Fig. 2. High resolution SEM images of the fracture surface of the hot-pressed composites: (a) Sample CMH which does not contain CNT showing a rather smooth surface due to a mainly transgranular fracture. (b)-(e) Samples C5, C10, CM2 and CM5, respectively, showing CNT emerging out of the surface fracture. The filaments appear more numerous and more widely interconnected. The matrix grains become smaller in C10 and CM2 due to the more pronounced grain-growth inhibition effect of CNT and the fracture becomes mainly intergranular. Note that CNT which have been broken at the level of the fracture surface can not be seen on these images, resulting in an under-estimation of the real quantity of CNT. (f) Sample CM12 showing many CNT emerging out of large pores and straightened before breaking during the fracture. 
grain seems still smaller and the filaments appear more numerous and more widely interconnected. On the CM12 image (Fig. 2(f)), large pores are apparent and many CNT, probably initially located within these pores, have been straightened before breaking during the fracture.

The DC electrical conductivities of the present hotpressed composites are reported in Table 1 and plotted in Fig. 3. Firstly, note that the $\mathrm{CMH}$ sample, which contains more metal than any of the other composites, is insulating $\left(\sigma=10^{-10} \mathrm{~S} \mathrm{~cm}^{-1}\right)$ like the $\mathrm{C} 1, \mathrm{C} 2$ and $\mathrm{C} 3$
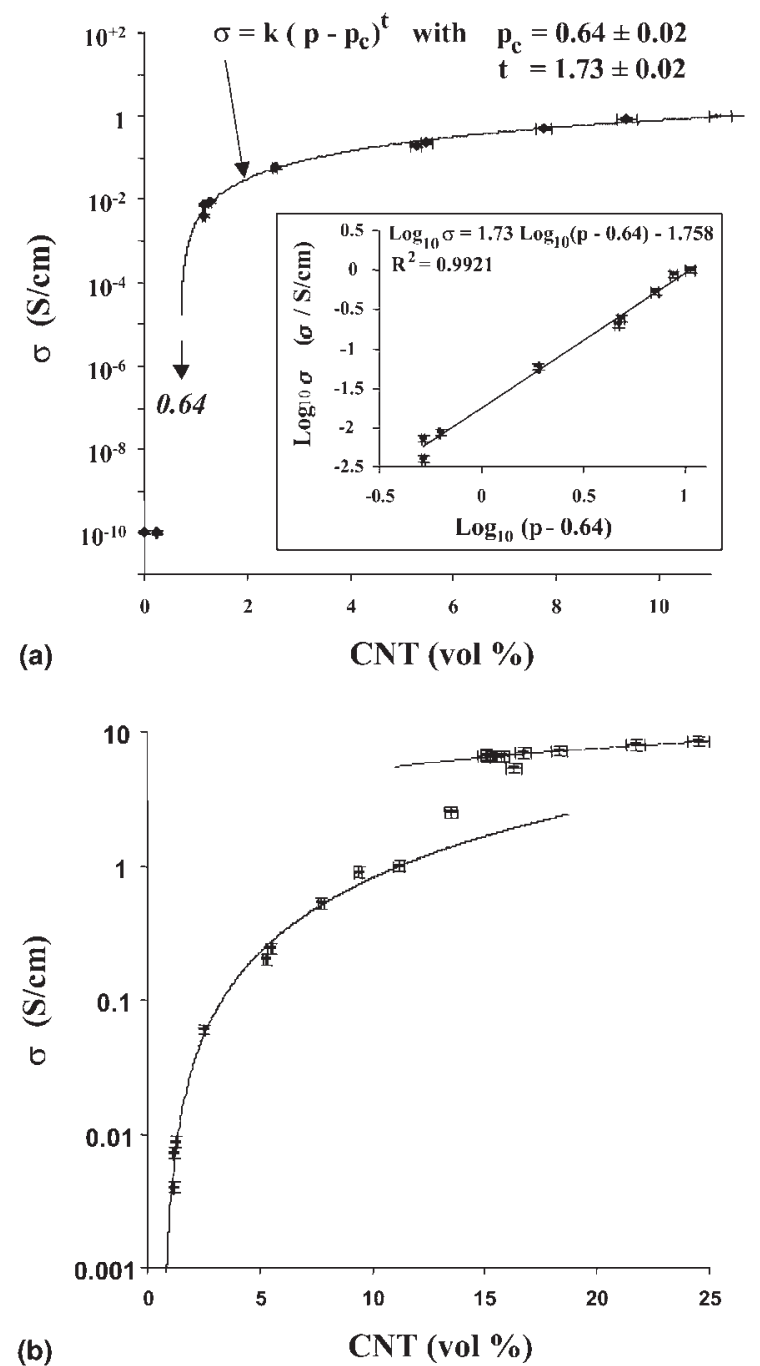

Fig. 3. Electrical conductivity $(\sigma)$ of the hot-pressed $\mathrm{CNT}-\mathrm{MgAl}_{2} \mathrm{O}_{4}$ composites as a function of the CNT content: (a) Plot in the range 0-11 vol $\%$ CNT showing a jump of $\sigma$ of seven orders of magnitude (from $10^{-10}$ to $\left.0.004 \mathrm{~S} \mathrm{~cm}^{-1}\right)$ between samples $\mathrm{C} 3(0.23 \mathrm{vol} \% \mathrm{CNT})$ and $\mathrm{C} 4$ (1.16 vol\% CNT) followed by a regular increase up to $1 \mathrm{~S} \mathrm{~cm}^{-1}$ for $11.18 \mathrm{vol} \%$ of CNT. The inserted plot in a $\log -\log$ scale shows that the $\sigma$ values are well fitted by the scaling law of the percolation theory with a percolation threshold $p_{\mathrm{c}}=0.64 \pm 0.02 \mathrm{vol} \%$ and an exponent $t=1.73 \pm 0.02$. (b) Plot in the range $0-25 \mathrm{vol} \% \mathrm{CNT}$ showing a sudden variation of $\sigma$ for CNT contents between 11 and $15 \mathrm{vol} \%$ CNT (CM4) and then a slight regular increase up to $8.53 \mathrm{~S} \mathrm{~cm}^{-1}$. composites $(0.23$ vol $\%$ CNT). A conductivity seven orders of magnitude higher $\left(0.0040 \mathrm{~S} \mathrm{~cm}^{-1}\right)$ was measured for the sample C4. For the C4-CM2 samples, the conductivity regularly increases up to $1 \mathrm{~S} \mathrm{~cm}^{-1}$ for $5.1 \mathrm{wt} \%$ of CNT (11.18 vol\%). These values are in the same range than that measured by Flahaut et al. [16] on similar composites $\left(1.5-1.8 \mathrm{~S} \mathrm{~cm}^{-1}\right.$ for $4.9 \mathrm{wt} \%$ of CNT). According to the percolation theory [24], the increase of the electrical conductivity $(\sigma)$ of the composites with the CNT volume fraction should obey to the scaling law $\sigma=k\left(p-p_{\mathrm{c}}\right)^{t}$, with $p$ the volume fraction of CNT and $p_{\mathrm{c}}$ the critical volume fraction corresponding to the percolation threshold. The exponent $t$ reflects the dimensionality of the system, the values 1.3 and 1.94 corresponding to two and three dimensions, respectively [24]. For samples C4-CM2 in which the CNT content is in the zone of supposed validity of the scaling law $\left(p>p_{\mathrm{c}}\right.$ and $\left(p-p_{\mathrm{c}}\right)$ small) we have inserted in Fig. 3(a) the plot of $\sigma$ versus the CNT volumic content in a $\log$ $\log$ scale. The $\sigma$ values are well fitted by the scaling law, the better adjustment being obtained for a percolation threshold $p_{\mathrm{c}}=0.64 \pm 0.02 \mathrm{vol} \%$ (about $0.31 \mathrm{wt} \%$ ) and an exponent $t=1.73 \pm 0.02$. Many authors have verified the scaling law on CNT-polymer composites [8-12]. Various values have been reported, between $0.33 \mathrm{wt} \%[8]$ and $0.0025 \mathrm{wt} \%$ [11] for the percolation threshold and from 2.1 [8] to 1.2 [11] for the exponent $t$. Particularly, Barrau et al. [10,12], who prepared the CNT by a method similar to that used in the present work, obtained a threshold at $0.3 \mathrm{wt} \%$ or below $0.1 \mathrm{wt} \%$, depending on the composite preparation method and an exponent $t$ of $1.44 \pm 0.30$. These very low percolation thresholds have been attributed to the enormous aspect ratio of the CNT. However, the fact that the values of $t$ are generally lower than 1.94 would not be the sign of a two dimensional network but rather a consequence of weakly-connected parts in the network, due to polymer barriers between CNT resulting in a thermally-induced hopping transport [9]. In the present study on ceramicmatrix composite, most CNT being SWNT and their distribution being very homogeneous as a consequence of their in situ synthesis, we expected to observe a percolation threshold at least as low as that obtained with polymer-matrix composites, which are prepared by mixing methods. But it is difficult to evaluate the exact degree of damage sustained by the CNT during the hotpressing at $1300{ }^{\circ} \mathrm{C}$, under vacuum, but in the solid oxide environment. The threshold could be overestimated either because the effective CNT content in the dense composites is lower than that in the starting composite powder, or because defects have been induced on some CNT, resulting in insulating or insufficiently conductive ramifications in the network. Thus, the effective percolation threshold may be lower than 0.64 $\mathrm{vol} \%$ and the probable existence of paths with a low conductivity due to damages of some CNT could ex- 
plain that the exponent is smaller than 1.94. The fact that, as the CNT content increases, they gather more and more in bundles which have a smaller aspect ratio than individual CNT could also explain the lower $t$ exponent.

For a CNT content higher than $11.18 \mathrm{vol} \%$, a more sudden variation appears for CM3 and CM4 with a conductivity reaching $6.59 \mathrm{~S} \mathrm{~cm}^{-1}$ for $15.13 \mathrm{vol} \% \mathrm{CNT}$ (CM4). Then, when the CNT content is increased from 15 to about $25 \mathrm{vol} \%$, the electrical conductivity presents only a slight regular increase up to $8.53 \mathrm{~S} \mathrm{~cm}^{-1}$ (CM12). The sudden $\sigma$ variation around $13 \mathrm{vol} \%$ CNT could be due to the fact that, in this composition range, the densification becomes very low $(<85 \%)$ which corresponds to the presence of open porosity in the material. Consequently, the CNT and CNT bundles which are located in this open porosity are probably interconnected without a significant interaction with the oxide matrix and thus are less damaged than CNT located at the matrix grain boundary or captured by the matrix grain. But even for the higher CNT content (CM12, $24.48 \mathrm{vol} \%$ ), the present composites have a conductivity lower than that reported by Zhan et al. [18] for CNT$\mathrm{Al}_{2} \mathrm{O}_{3}$ composites $\left(33.45 \mathrm{~S} \mathrm{~cm}^{-1}\right.$ for only $10 \mathrm{vol} \% \mathrm{CNT}$ ). The difference in the oxide matrix, in the preparation routes (mixing of the components, SPS treatment allowing a very short heating at high temperature) and in the CNT characteristics all probably concur to a lesser damaging of CNT in their study [18].

\section{Conclusions}

In the present work, we have for the first time characterised and quantified the percolation of SWNT in an insulating ceramic matrix and showed that the scaling law is valid in this new class of composite materials. In order to achieve this, a family of SWNT- $\mathrm{MgAl}_{2} \mathrm{O}_{4}$ massive composites has been prepared, in a wide range of composition (0.23-24.5 vol\% CNT) and with a very homogeneous distribution of the SWNT between the matrix grains owing to the in situ CCVD synthesis route. A jump of the DC electrical conductivity of seven order of magnitude $\left(10^{-10}-0.0040 \mathrm{~S} \mathrm{~cm}^{-1}\right)$ has been measured between 0.23 and $1.16 \mathrm{vol} \%(0.11-0.55 \mathrm{wt} \%)$. Up to 11 $\mathrm{vol} \% \mathrm{CNT}$, the electrical conductivity is well fitted by the scaling law of the percolation theory $\sigma=k\left(p-p_{\mathrm{c}}\right)^{t}$ with a percolation threshold $p_{\mathrm{c}}=0.64 \mathrm{vol} \% \mathrm{CNT}$ (about 0.31 $\mathrm{wt} \%$ ) and an exponent $t=1.73$. Comparing with CNTpolymer composites ( $p_{\mathrm{c}}$ between 0.33 and $0.0025 \mathrm{wt} \%$ ) [8-12], the percolation threshold is higher, but probably is overestimated owing to some degree of damage sustained by the CNT during hot-pressing at $1300^{\circ} \mathrm{C}$ under vacuum in a solid oxide environment. The existence of damaged ramifications in the CNT network and the bundling of CNT upon an increased content could ex- plain the little difference between the experimental exponent $(t=1.73)$ and the theoretical one $(t=1.94)$ characteristic of a tri-dimensional network [24]. The conductivity of the present SWNT- $\mathrm{MgAl}_{2} \mathrm{O}_{4}$ composites can be tailored in the $0.004-8.5 \mathrm{~S} \mathrm{~cm}^{-1}$ range directly by controlling the CNT content. For small CNT contents $(1-2.5 \mathrm{vol} \%)$, the conductivity is sufficient to assure an efficient electrical discharge to the insulating ceramic, and furthermore the densification of the composites is easily achieved by hot-pressing, so alterations of the other intrinsic properties of the ceramic matrix are probably avoided. CNT-ceramic composites become attractive materials not only for their enhanced mechanical properties [2-7], but also for the possibility to tailor their electrical conductivity directly by the quantity of CNT.

\section{References}

[1] Laurent Ch, Peigney A. In: Nalwa HS, editor. Encyclopedia of nanoscience and nanotechnology. American Scientific Publisher [in press].

[2] Zhan G-D, Kuntz JD, Wan J, Mukherjee AK. Nat Mater 2003;2:38

[3] Ning J, Zhang JYP, Guo J. Mater Sci Eng 2003;A357.

[4] Sun J, Gao L, Li W. Chem Mater 2002;14:5169.

[5] Siegel RW, Chang SK, Ash BJ, Stone J, Ajayan PM, Doremus RW, Schadler LS. Scripta Mater 2001;44:2061.

[6] Peigney A. Nat Mater 2003;2:15.

[7] An JW, Lim DS. J Ceram Proc Res 2002;3:118.

[8] Benoit JM, Corraze B, Lefrant S, Blau WJ, Bernier P, Chauvet O. Synth Met 2001;121:1215.

[9] Kilbride BE, Coleman JN, Fraysse J, Fournet P, Cadek M, Drury A, Hutzler S, Roth S, Blau WJ. J Appl Phys 2002;92:4024.

[10] Barrau S, Demont P, Peigney A, Laurent Ch, Lacabanne C. Macromol 2003;36:5187.

[11] Sandler JKW, Kirk JE, Kinloch IA, Shaffer MSP, Windle AH. Polymer 2003;44:5893.

[12] Barrau S, Demont P, Perez E, Peigney A, Laurent Ch, Lacabanne C. Macromol. [in press].

[13] Peigney A, Laurent Ch, Dobigeon F, Rousset A. J Mater Res 1997;12:613.

[14] Laurent Ch, Peigney A, Dumortier O, Rousset A. J Eur Ceram Soc 1998;18:2005.

[15] Peigney A, Laurent Ch, Flahaut E, Rousset A. Ceram Int 2000;26:677.

[16] Flahaut E, Peigney A, Laurent Ch, Marliere C, Chastel F, Rousset A. Acta Mater 2000;48:3803.

[17] Peigney A, Flahaut E, Laurent Ch, Chastel F, Rousset A. Chem Phys Lett 2002;352:20.

[18] Zhan G-D, Kuntz JD, Garay JE, Mukherjee AK. Appl Phys Lett 2003;83:1228.

[19] Govindaraj A, Flahaut E, Laurent Ch, Peigney A, Rousset A, Rao CNR. J Mater Res 1999;14:2567.

[20] Rul S, Laurent Ch, Peigney A, Rousset A. J Eur Ceram Soc 2003:1233-41.

[21] Peigney A, Coquay P, Flahaut E, Vandenberghe RE, De Grave E, Laurent Ch. J Phys Chem B 2001;105:9699.

[22] Tang S, Zhong Z, Xiong Z, Sun L, Liu L, Lin J, Shen ZX, Tan KL. Chem Phys Lett 2001;350:19.

[23] Laurent Ch, Rousset A. Key Eng Mater 1995;108-110:405.

[24] Stauffer D. Introduction to the percolation theory. London and Philadelphia: Taylor \& Francis; 1985. 